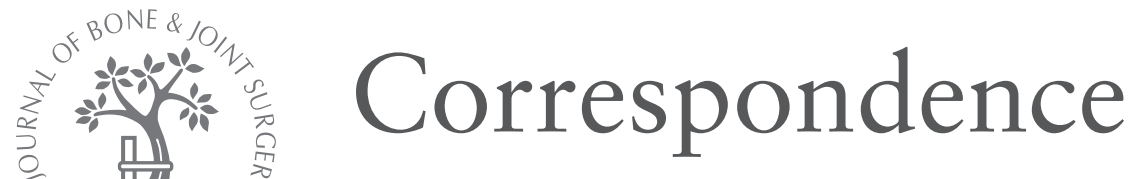

We welcome letters to the Editor concerning articles which have recently been published. Such letters will be subject to the usual stages of selection and editing; where appropriate the authors of the original article will be offered the opportunity to reply.

Letters should normally be under $\mathbf{3 0 0}$ words in length, doublespaced throughout, signed by all authors and fully referenced. The edited version will be returned for approval before publication.

(C)2006 British Editorial Society of Bone and Joint Surgery \$2.00 J Bone Joint Surg [Br] 2006;88-B:1676-7.

\section{The premature failure of the Charnley Elite-Plus stem}

Sir,

We read with interest the article by Hauptfleisch et $\mathrm{al}^{1}$ in the February 2006 issue entitled 'The premature failure of the Charnley Elite-Plus stem: a confirmation of RSA predictions'. The authors found that the survival of Elite-Plus femoral components at ten years was $83 \%$, dropping to $59 \%$ when stems deemed radiologically loose were included. In a sub-group of 19 components, a roentgen stereophotogrammetric analysis (RSA) had correctly predicted the failure of four. Blame for the poor survival rate was apportioned to the design of the prosthesis. Compared with the Exeter hip, they consider it to be less 'forgiving', requiring 'perfect' cementing to ensure a good long-term outcome. ${ }^{2}$

We have carried out a three-year RSA study of 25 Elite-Plus femoral components and have only one potential failure (paper in preparation). Additional measurements or assessments, which we believe are essential in order to judge the cause of failure, ${ }^{3}$ were not carried out by the authors. In particular, Barrack, Mulroy and Harris ${ }^{4}$ cementing grades were not assessed and so we do not know whether the radiolucencies found at ten years were present post-operatively.

The authors have published three papers on RSA of the ElitePlus, ${ }^{5-7}$ but this is the first time that they have revealed that lowviscosity cement had been used in all cases. It is surprising that the authors did not refer to the paper by Walton et $\mathrm{al}^{8}$ (published in this journal four months before they submitted their paper) which showed that the Elite-Plus performed significantly worse with lowviscosity cement than with high-viscosity cement. This finding is in line with studies of the Norwegian Arthroplasty Register which showed an increased failure rate of the Charnley hip associated with low-viscosity cement. ${ }^{9,10}$ Low-viscosity cements such as Sulfix and CMW3 are no longer used in Norway and Sweden. ${ }^{10}$

The authors reject the possibility that cement or surgical technique might be the cause of the high failure rate because they used the same cement and technique on Exeter stems, which performed much better. Indeed, in a 12-month RSA study, the Oxford group found no significant differences in the migrations of Exeter hips when low, medium or high-viscosity cements were used. ${ }^{11}$ However, Furnes et $\mathrm{al}^{12}$ found that Exeter stems had a lower failure rate than Charnley stems when Boneloc cement was used, and this suggests that low/medium-viscosity cement might be more tolerant to 'force closed' prostheses, ${ }^{13}$ such as the Exeter.

In the case of the Elite-Plus, therefore, we suggest that it might well be the low-viscosity cement that is not very forgiving, rather than the stem itself.

doi:10.1302/0301-620X.88B12.18852

B. DERBYSHIRE, PhD, Research Fellow

M. L. PORTER, FRCS, Consultant Orthopaedic Surgeon Wrightington Hospital,

Wigan, UK.

1. Hauptfleisch J, Glyn-Jones S, Beard DJ, Gill HS, Murray DW. The premature failure of the Charnley Elite-Plus stem: a confirmation of RSA predictions. J Bone Joint Surg [Br] 2006;88-B:179-83.

2. Sherretta SB. Charnley Elite Plus follow-up confirms RSA predictions of high early failure rate. $\mathrm{http}: / /$ www.orthosupersite.com/default.asp? page $=$ void\&rid $=3909$ (accessed 08/02/06).

3. Porter ML, Derbyshire B. Letter to the Editor. J Arthroplasty 2003;18:121-2.

4. Barrack RL, Mulroy RD, Harris WH. Improved cementing technique and femoral component loosening in young patients with hip arthroplasty. J Bone Joint Surg [Br] 1992;74-B:385-9.

5. Alfaro-Adrian J, Gill HS, Murray DW. Cement migration after THR. J Bone Joint Surg [Br] 1999;81-B:130-4.

6. Alfaro-Adrian J, Gill HS, Murray DW. Should total hip arthroplasty femoral components be designed to subside? A radiostereometric analysis study of the Charnley and Exeter stems. J Arthroplasty 2001;16:598-606.

7. Gill HS, Alfaro-Adrian J, Alfaro-Adrian C, McLardy-Smith P, Murray DW. The effect of anteversion on femoral component stability assessed by radiostereometric analysis. J Arthroplasty 2002;17:997-1005.

8. Walton NP, Darrah C, Shepstone L, Donell ST, Phillips H. The Elite Plus total hip arthroplasty. J Bone Joint Surg [Br] 2005;87-B:458-62.

9. Havelin LI, Espehaug B, Vollset SE, Engesaeter LB. The effect of the type of cement on early revision of Charnley total hip prostheses: a review of eight thousand five hundred and seventy-nine primary arthroplasties from the Norwegian Arthroplasty Register. J Bone Joint Surg [Am] 1995;77-A:1543-50.

10. Espehaug B, Furnes O, Havelin LI, Engesaeter LB, Vollset SE. The type of cement and failure of total hip replacements. J Bone Joint Surg [Br]2002;84-B:832-8.

11. Glyn-Jones S, Hicks J, Alfaro-Adrian J. The influence of cement viscosity on the early migration of a tapered polished femoral stem. Int Orthop 2003;27:362-5.

12. Furnes $\mathbf{0}$, Lie SA, Havelin LI, Vollset SE, Engesaeter LB. Exeter and Charnley arthroplasties with Boneloc or high viscosity cement: comparison of 1127 arthroplasties followed for 5 years in the Norwegian Arthroplasty Register. Acta Orthop Scand 1997;68:515-20.

13. Huiskes R, Verdonschot N, Nivbrant B. Migration, stem shape, and surface finish in cemented total hip arthroplasty. Clin Orthop 1998;355:103-12.

\section{Author's reply:}

Sir,

We would like to thank Mr Derbyshire and Mr Porter for their interest in our paper.

For our study of the Elite-Plus stem we used a cement gun. We therefore selected CMW3 cement, which was the low-viscosity cement made by the manufacturer of the stem.

Our results were disappointing and not as good as those achieved by other authors. The difference in results is likely to be because of differences in surgical technique or cement. When we used identical techniques and cement with the Exeter stem we 
achieved good results. We therefore concluded that the Elite-Plus stem was not as forgiving as the Exeter stem. We stand by this conclusion, as we believe that the outcome of polished tapered stems is less likely to be influenced by both surgical technique ${ }^{1}$ and cement type. ${ }^{2}$

Mr Derbyshire and Mr Porter make the suggestion that low-viscosity cement is less forgiving than high viscosity. This may well be true. However, to establish this we would need evidence that errors in surgical technique cause failure with low-viscosity cement but do not cause failure with high-viscosity cement.

doi:10.1302/0301-620X.88B12.18853

D. W. MURRAY, FRCS, Professor

H. S. GILL, DPhil, University Research Lecturer

Nuffield Department of Orthopaedic Surgery,

University of Oxford, Oxford, UK.

1. Gill HS, Alfaro-Adrian J, Alfaro-Adrian C, McLardy-Smith P, Murray DW. The effect of anteversion on femoral component stability assessed by radiostereometric analysis. J Arthroplasty 2002;17:997-1005.

2. Glyn-Jones S, Hicks J, Alfaro-Adrian J. The influence of cement viscosity on the early migration of a tapered polished femoral stem. Int Orthop 2003:27:362-5.

\section{The premature failure of the Charnley Elite-Plus stem}

Sir,

I read with interest the article by Hauptfleisch et al. ${ }^{1}$ DePuy International Ltd has to date not commented on the data presented by the authors, in various publications, on the performance of the Elite-Plus system. However, we consider that the publication of the above paper requires a response because firstly, the conclusions may cause unnecessary concern to surgeons who have used the Elite-Plus system and the many thousands of patients who have been the recipients of this device. Secondly, information pertinent to the conclusions of this paper was omitted by the authors in the original publication.

The results presented in the above publication were derived from a research study which was designed by the Oxford group and grant-funded by DePuy International Ltd. The outcome of this RSA-like study was followed closely. The results were openly shared and discussed between our research groups. When the twoyear follow-up data became available, this was reviewed. It appeared that the posterior migration/rotation of the Elite-Plus stems was greater than that of the comparator system. An examination of the data showed that the difference in posterior migration was not a normal distribution and that four outliers were the principle cause of the difference. If these were excluded then the two cohorts had similar levels of posterior migration. In an attempt to explain these differences a representative of DePuy (GHI), who had no prior access to the outcome data for individual patients, was invited to review 14 sets of Elite-Plus radiographs from the study. A number of factors were reviewed, including stem position, orientation, cement mantle thickness, and cement mantle quality.

A notable observation was that nine of ten patients in the stable group were registered as having a good cement mantle (as opposed to satisfactory), whilst only one of four was recorded in the unstable group. A further observation was that three patients were identified as having inadequate proximomedial cement support ("virtually no cement mantle", "very little cement", and "low neck resection"). When these patients were matched with the RSA data it was found that they were contained within the group of four that had higher than average posterior migration. These observations (together with others) on the appearance of the cement mantle were communicated, verbally and in writing, to the authors who concluded "none of your measurements have a significant relationship to posterior head migration". A further communication was sent to the authors highlighting the relevant observations and concluding, "whilst not proven, these small numbers hint that the quality of the cement mantle may be a factor which influences stability", and that the majority of stems with high posterior movement had "radiographic features which would make instability more likely". Further comments were sought, however,not only the current paper $^{1}$ but also a previous publication on this study ${ }^{2}$ completely ignored these issues, and the relationship to radiographic appearance was not discussed.

Given the radiographic appearance it is not entirely surprising that these high posterior migration components subsequently went on to fail. Furthermore, it reinforces the belief that the performance of cemented stems is as much dependent upon the quality of cementation as it is on stem design.

doi:10.1302/0301-620X.88B12.18855

G. H. ISAAC, PhD, Senior Engineering Fellow - Hips

DePuy International Ltd.

Visiting Professor,

University of Leeds, UK.

1. Hauptfleisch J, Glyn-Jones S, Beard DJ, Gill HS, Murray DW. The premature failure of the Charnley Elite-Plus stem: a confirmation of RSA predictions. J Bone Joint Surg [Br] 2006;88-B:179-83.

2. Alfaro-Adrian J, Gill HS, Murray DW. Should total hip arthroplasty femoral components be designed to subside? A radiostereometric analysis study of the Charnley and Exeter stems. J Arthroplasty 2001;16:598-606.

\section{Author's reply:}

Sir,

We completely agree with Dr Isaac that the outcome of a hip replacement depends on both the surgical technique and the stem design. In our paper we pointed out that other centres had achieved better results than we had with the Elite-Plus stem, and that this was probably due to differences in surgical technique. We had also previously conducted a detailed study ${ }^{1}$ to determine which factors were responsible for the failures. In this study we looked at various factors relating to the patient, cementing and surgical technique in patients that we had correctly predicted would fail, and we compared these with those that did not fail. The assessment of cementing was done in a blinded fashion by Dr Isaac. Interestingly, we found that lack of stem anteversion was significantly related to failure. We did not find any statistically-significant relationship between quality of cementing and failure, although this may have been because the numbers studied were small.

We are very grateful for the funding provided by DePuy and for the help and support Dr Isaac has given us throughout the study. doi:10.1302/0301-620X.88B12.18856

D. W. MURRAY, FRCS, Professor

H. S. GILL, DPhil, University Research Lecture

Nuffield Department of Orthopaedic Surgery,

University of Oxford, Oxford, UK.

1. Gill HS, Alfaro-Adrian J, Alfaro-Adrian C, McLardy-Smith P, Murray DW. The effect of anteversion on femoral component stability assessed by radiostereometric analysis. J Arthroplasty 2002:17:997-1005. 